\title{
UTILIZAÇÃO DE DOIS MÉTODOS DE INOCULAÇÃO NA AVALIAÇÃO DA RESISTENCIA DE CULTIVARES E LINHAGENS DE FEIJOEIRO A Fusarium oxysporum F. SP. phaseoli
}

\author{
USE OF TWO INOCULATION METHODS TO EVALUATE THE RESISTANCE OF COMMON \\ BEAN CULTIVARS AND LINES TO Fusarium oxysporum F. SP. phaseoli
}

\section{Leonardo Sousa Cavalcanti ${ }^{1}$ Rildo Sartori Barbosa Coêlho ${ }^{2}$ Jane Oliveira Perez ${ }^{3}$}

RESUMO

Este trabalho foi conduzido com o objetivo de comparar a eficiência de dois métodos de inoculação na avaliação da resistência de plantas de feijoeiro a Fusarium oxysporum $f$. sp. phaseoli. Avaliou-se a reação de 16 cultivares e linhagens, incluindo padrões de resistência e suscetibilidade à doença. Num dos métodos, o plantio foi realizado em solo tratado com brometo de metila $\left(\mathrm{CH}_{3} \mathrm{Br}\right)$. As plantas foram inoculadas através do método de perfuração do solo, que consistiu na aplicação de $10 m \ell$ de suspensão de conídios ao redor das plantas, previamente feridas. No outro método utilizado, denominado método de imersão de raízes, as plantas obtidas em areia lavada e aquecida $\left(60^{\circ} \mathrm{C}-30 \mathrm{~min}\right)$ foram retiradas e lavadas em água corrente e cortadas em cerca de $01 \mathrm{~cm}$ do sistema radicular, o qual foi imerso em suspensão de conídios por 05 minutos. As plantas foram então replantadas em vasos contendo solo tratado com brometo de metila. Em ambos os métodos de inoculação, as plantas estavam com 07 dias de germinação, sendo inoculadas com a suspensão de inóculo a uma concentração de $1 \times 10^{6}$ conídios $/ m \ell$. As plantas controle sofreram o mesmo tratamento, referente ao método de inoculação correspondente. $O$ experimento foi delineado inteiramente ao acaso, em parcelas subdivididas, com 04 repetições por tratamento, sendo o método de inoculação locado na parcela principal $e$ as cultivares e linhagens nas subparcelas. Cada repetição foi constituída por 01 vaso com 04 plantas. As avaliações foram realizadas aos 15, 20, 25 e 30 dias após a inoculação, baseadas em escala de notas, com 9 graus de infecção, proposta pelo CIAT. Os dados obtidos foram transformados para índice de doença de Mackinney. Observou-se uma maior eficiência do método de imersão das raízes, na avaliação da resistência do feijoeiro a murcha de Fusarium, evidenciando os genótipos Goiano precoce, RH 3104 e IPA-9 como resistentes, e LM 93204247, LM 93204296 e IPA-1 como suscetíveis.

\begin{abstract}
Palavras-chave: resistência de cultivares, murcha de Fusarium.
\end{abstract}
\section{SUMMARY}

This experiment was conducted aiming to study the efficiency of two inoculation methods to evaluate the resistance of common bean to Fusarium oxysporum $f$. sp. phaseoli. The reaction of 16 cultivars and lines tested, including resistant and suscetible patterns to the disease. In one of the methods, plants were inoculated by the soil perfuration method, which consists on the aplication of $10 \mathrm{~m} \ell$ of conidia suspension around, previously wounded plants. For the other method, named root immersion, the plants obtained in washed and warmed up sand $\left(60^{\circ} \mathrm{C}-30 \mathrm{~min}\right)$ were extracted, washed with running water, and tipped about one centimeter from their roots, which were submersed into conidia suspension for 05 minutes. Then, plants were replanted in plastic pots with treated soil. Two inoculation procedures were performed after seven days from plant emergence. A suspension containing $1 \times 10^{6}$ conidia/m $\ell$ was used in both inoculation methods. The experiment was performed in completely randomized split-plot design, with 04 replicates per treatment. Each replicate consisted of one plastic pot containing four plants. The evaluations were carried out 15, 20, 25 and 30 days after each inoculation procedure. A grading scale, proposed by CIAT, considering levels of infection ranging from 1 (highly resistant) to 9 (highly suscetible) was used. The data were converted to Mackinney disease index. The root immersion method presented better efficacy than soil perfuration method to assess commom bean resistance to Fusarium wilt, evidencing Goiano precoce, RH 3104 and IPA-9 cultivars as the most resistant genotypes, and LM 93204247, LM 93204296 and IPA-1 as the most susceptible ones.

Key words: cultivar resistance, Fusarium wilt.

\footnotetext{
${ }^{1}$ Engenheiro Agrônomo, Mestre em Fitopatologia, Estudante de Doutorado, Setor Fitopatologia, Escola Superior de Agricultura Luiz de Queiróz, Universidade de São Paulo, CP 9, 13418-900, Piracicaba, SP. E-mail: lescaval@esalq.usp.br. Autor para correspondência. ${ }^{2}$ Engenheiro Agrônomo, Doutor em Fitopatologia, Pesquisador, Empresa Pernambucana de Pesquisa Agropecuária, IPA, Recife-PE. ${ }^{3}$ Engenheiro Agrônomo, Mestre em Fitopatologia, Estudante de Doutorado, Departamento de Fitopatologia, Universidade Federal de Lavras, Lavras-MG.
} 


\section{INTRODUÇÃO}

A cultura do feijoeiro comum representa uma das principais fontes de nutrientes e sais minerais da dieta alimentar da população brasileira. A sua produtividade vem apresentando elevada taxa de crescimento, tendo aumentado de $638 \mathrm{~kg} / \mathrm{ha}$ para $1879 \mathrm{~kg} / \mathrm{ha}$, em um período de apenas cinco anos (IBGE, 1993 / 1998). Isto se deve principalmente à utilização de tecnologias de produção diferenciadas, tais como o cultivo sob pivô central, que tem proporcionado a possibilidade de plantios sucessivos, com conseqüente aumento da rentabilidade da cultura. Apesar de possibilitarem o aumento da produtividade e do número de safras durante o ano, tais tecnologias criam condições de umidade e temperatura ideais ao desenvolvimento de patógenos, favorecendo a ocorrência de algumas doenças que apresentam alto risco à produção.

Dentre estas doenças, destaca-se a murcha de Fusarium, causada por Fusarium oxysporum Schlecht. f. sp. phaseoli Kendrick e Snyder. Essa enfermidade tem causado grandes perdas nas lavouras de feijão devido, principalmente, aos cultivos sucessivos, possibilitados pela prática da irrigação (RAVA et $\boldsymbol{a l}$., 1996) e a uma maior disseminação do patógeno por meio de implementos agrícolas em cultivos mecanizados (ROCHA JÚNIOR et al., 1998). A doença caracteriza-se por clorose e lesões necróticas a partir das folhas mais velhas, com posterior murcha, desfolhamento prematuro e nanismo. Seu sintoma característico é observado mediante cortes transversal e longitudinal, representado pelo escurecimento dos vasos do xilema.

O fungo sobrevive em restos de cultura e no solo, através de estruturas de resistência, o que dificulta o controle cultural e químico, em áreas de constante exploração desta cultura.

A utilização de cultivares resistentes representa a medida mais eficiente e econômica para o controle dessa doença (SARTORATO E RAVA, 1994). Diversas pesquisas buscam a obtenção de fontes de resistência a murcha de Fusarium, em cultivares e linhagens de alto potencial agrícola (CRUZ $\boldsymbol{e}$ t al., 1974; RIBEIRO E FERRAZ, 1984; PASTOR-CORRALES E ABAWI, 1987; ZAMBOLIM et al., 1987; PIZA, 1993; NASCIMENTO $\boldsymbol{e}$ t al., 1995; ROCHA JÚNIOR $\boldsymbol{e} \boldsymbol{t}$ al., 1998). Nesses estudos, é necessária a utilização de uma metodologia de inoculação eficiente e confiável, que possibilite o estabelecimento e desenvolvimento do patógeno. Diferentes metodologias de inoculação, tipos e concentrações de inóculo vêm sendo utilizadas para avaliar a severidade desta doença, como nos trabalhos de PASTOR-CORRALES E ABAWI, (1987); FERREIRA (1983) e NASCIMENTO et al. (1995; 1998), sem que haja uma padronização da metodologia de inoculação, o que pode incorrer em erros quanto ao comportamento de cultivares e linhagens de feijoeiro frente a $\boldsymbol{F}$. oxysporum f. sp. phaseoli .

O objetivo do presente trabalho foi comparar métodos de inoculação utilizados na avaliação da severidade da murcha de Fusarium, através da reação de cultivares e linhagens de feijoeiro ao patógeno, com o intuito de incentivar a padronização de uma metodologia de inoculação, que possibilite a identificação de fontes promissoras para o melhoramento genético visando resistência a esta doença que, cada vez mais, tem sua relevância econômica aumentada, principalmente em plantios sucessivos, possibilitados pelo advento da irrigação.

\section{MATERIAL E MÉTODOS}

Dezesseis cultivares e linhagens de feijoeiro (Phaseolus vulgaris L.) foram avaliadas quanto à reação a um isolado de $\boldsymbol{F}$. oxysporum $\mathrm{f}$. sp. phaseoli, obtido no Município de Belém do São Francisco, Estado de Pernambuco. Dois métodos de inoculação foram avaliados. Em um dos métodos utilizados, denominado método de perfuração do solo, descrito por MENEZES (1972) e citado por FERREIRA (1983), o plantio foi realizado em vasos plásticos, de $15 \mathrm{~cm}$ de diâmetro, contendo solo tratado com brometo de metila $\left(\mathrm{CH}_{3} \mathrm{Br}\right)$.

Foram realizadas perfurações no solo ao redor das plantas, com auxílio de escalpelo, com posterior distribuição de $20 \mathrm{~m} \ell$ de suspensão de conídios $\left(1 \times 10^{6}\right.$ conídios $\left./ \mathrm{m} \ell\right)$. No outro método utilizado, denominado método de imersão das raízes, as plantas foram obtidas através da semeadura em bandejas plásticas, contendo areia lavada e aquecida durante $30 \mathrm{~min}$ a $60^{\circ} \mathrm{C}$. Este método baseou-se na imersão do sistema radicular, previamente cortado a cerca de $1 \mathrm{~cm}$ da coifa, durante 05 minutos, em suspensão de conídios ( $1 \mathrm{x} 10^{6}$ conídios $\left./ \mathrm{m} \ell\right)$, e posterior replantio em vasos plásticos, contendo solo tratado com brometo de metila. Em ambos os métodos, as plantas estavam com 07 dias de germinação, sendo fertilizadas quinzenalmente com $50 \mathrm{~m} \ell$ de solução NPK (20-10-20) a $0,3 \%(\mathrm{~m} / \mathrm{v})$ (PASTOR-CORRALES E ABAWI, 1987).

$\mathrm{O}$ inóculo foi obtido através da adição de $10 \mathrm{~m} \ell$ de água destilada às placas de Petri, contendo as colônias do fungo, cultivadas em meio BDA (Batata - dextrose-agar), durante 15 dias, a uma 
temperatura de $25 \pm 2^{\circ} \mathrm{C}$. Após a filtração, em quatro camadas de gaze esterilizada, a suspensão foi centrifugada a 5000rpm, por 5 minutos, sendo o precipitado suspendido em água destilada, e novamente centrifugado. Em seguida, promoveu-se a ressuspensão e ajuste da concentração do inóculo, com auxílio de uma câmara de Neubauer, para 1x $10^{6}$ conídios/m $\ell$ (PASTOR-CORRALES E ABAWI, 1987).

As avaliações foram realizadas aos 15, 20, 25 e 30 dias após a inoculação, utilizando-se escala de notas adotada pelo Centro Internacional de Agricultura Tropical - CIAT, Cali, Colômbia, descrita por SCHOONHOVEN \& PASTORCORRALES (1987), com notas de 1 a 9. A nota 1 corresponde a plantas sem sintomas perceptíveis; nota 3 - atribuída a plantas com algumas folhas murchas, representando não mais que $10 \%$ da folhagem, com pequenas lesões no hipocótilo; nota 5 atribuída a plantas com aproximadamente $25 \%$ das folhas com sintomas de murcha e clorose; nota 7 cerca de $50 \%$ das folhas exibindo sintomas de murcha, clorose e necroses limitadas; nota 9 plantas com sintomas de necrose com desfoliação precoce, clorose e murcha em $75 \%$ das folhas ou mais, plantas severamente atrofiadas e plantas mortas. Os dados originais foram transformados em Índice de doença de Mackinney (Tabela 1), conforme BALARDIN et al. (1990), tendo sido considerados três tipos de reação: resistente,

intermediário e suscetível, para índices até 33,33 ; 66,66 e $100 \%$, respectivamente. O delineamento experimental utilizado foi inteiramente casualizado, em parcelas subdivididas, sendo o método de inoculação locado na parcela principal, e as cultivares e linhagens nas subparcelas. Cada subparcela foi constituída por 01 vaso com 04 plantas.

\section{RESULTADOS E DISCUSSÃO}

As figuras 1 e 2 mostram o progresso da doença, em algumas cultivares e linhagens, possibilitando a comparação dos métodos de inoculação. A cultivar IPA 1 apresentou reação de resistência, quando inoculada através do método de perfuração do solo. Entretanto, mostrou-se suscetível aos 20 dias após a inoculação, quando inoculada por meio do método de imersão das raízes. Este resultado coincide com as informações relatadas por PASTORCORRALES \& ABAWI (1987); PIZA (1993); NASCIMENTO $\boldsymbol{e t}$ al. (1995) e RAVA $\boldsymbol{e t}$ al. (1996). A cultivar ESAL 647 e as linhagens AN 9022421 e LM 9324509 também não confirmaram, para o método de imersão das raízes, suas reações de resistente ou intermediária, que apresentaram quando inoculadas pelo método de perfuração do solo. Isto revela a maior eficiência do método de imersão das raízes, devido, possivelmente, a uma maior exposição da área das raízes aos conídios, aumentando a possibilidade de penetração do patógeno.

Tabela 1 - Reação de genótipos de feijoeiro, em diferentes períodos de avaliação, a $\boldsymbol{F u s a r i u m}$ oxysporum f. sp. phaseoli inoculados através do método de imersão de raízes. Recife, 1999 .

\begin{tabular}{|c|c|c|c|c|c|c|c|c|}
\hline \multirow{2}{*}{$\begin{array}{l}\text { Cultivar/ } \\
\text { Linhagem }\end{array}$} & \multicolumn{2}{|c|}{15 dias } & \multicolumn{2}{|c|}{20 dias } & \multicolumn{2}{|c|}{25 dias } & \multicolumn{2}{|c|}{30 dias } \\
\hline & $\begin{array}{l}\text { Ìndice de } \\
\text { doença* }\end{array}$ & Reação & $\begin{array}{l}\text { Ìndice de } \\
\text { doença* }\end{array}$ & Reação & $\begin{array}{l}\text { İndice de } \\
\text { doença* }\end{array}$ & Reação & $\begin{array}{c}\text { Ìndice de } \\
\text { doença* }\end{array}$ & Reação \\
\hline IPA-7 & 34,83 & I & 44,24 & I & 45,29 & I & 50,00 & I \\
\hline IPA-10 & 32,79 & $\mathrm{R}$ & 36,83 & I & 49,28 & I & 51,93 & I \\
\hline IPA-11 & 29,17 & $\mathrm{R}$ & 37,90 & I & 37,90 & I & 39,91 & I \\
\hline IPA-9 & 24,92 & $\mathrm{R}$ & 32,03 & $\mathrm{R}$ & 32,03 & $\mathrm{R}$ & 33,24 & $\mathrm{R}$ \\
\hline ESAL-647 & 28,67 & $\mathrm{R}$ & 34,39 & I & 36,11 & I & 60,77 & $\mathrm{~S}$ \\
\hline LM 93204247 & 64,83 & $\mathrm{~S}$ & 90,00 & $\mathrm{~S}$ & 90,00 & $\mathrm{~S}$ & 90,00 & $\mathrm{~S}$ \\
\hline LM 9324296 & 30,04 & $\mathrm{R}$ & 85,13 & $\mathrm{~S}$ & 86,05 & $\mathrm{~S}$ & 90,00 & $\mathrm{~S}$ \\
\hline AN 9022421 & 26,09 & $\mathrm{R}$ & 55,07 & I & 66,27 & I & 74,45 & $\mathrm{~S}$ \\
\hline RH 3104 & 27,16 & $\mathrm{R}$ & 28,29 & $\mathrm{R}$ & 30,51 & $\mathrm{R}$ & 31,61 & $\mathrm{R}$ \\
\hline LM 9220363 & 28,88 & $\mathrm{R}$ & 32,07 & $\mathrm{R}$ & 32,07 & $\mathrm{R}$ & 34,16 & I \\
\hline RH 3045 & 23,13 & $\mathrm{R}$ & 34,83 & I & 56,67 & I & 59,70 & I \\
\hline AN 9022180 & 22,55 & $\mathrm{R}$ & 39,60 & I & 49,25 & I & 56,56 & I \\
\hline AN 90221465 & 21,05 & $\mathrm{R}$ & 42,51 & I & 56,02 & I & 59,85 & I \\
\hline LM 9324509 & 19,47 & $\mathrm{R}$ & 57,74 & I & 75,19 & $\mathrm{~S}$ & 82,12 & $\mathrm{~S}$ \\
\hline IPA-1 & 19,47 & $\mathrm{R}$ & 75,21 & $\mathrm{~S}$ & 87,22 & $\mathrm{~S}$ & 90,00 & $\mathrm{~S}$ \\
\hline Goiano Precoce & 19,47 & $\mathrm{R}$ & 22,57 & $\mathrm{R}$ & 26,66 & $\mathrm{R}$ & 28,85 & $\mathrm{R}$ \\
\hline
\end{tabular}

* Índice de doença $=(\Sigma($ f.v $) / \mathrm{n} . \mathrm{x}) * 100 ; \mathrm{f}=\mathrm{n}^{\mathrm{o}}$ de plantas em cada categoria; $\mathrm{v}=$ nota; $\mathrm{n}=\mathrm{n}^{\mathrm{o}}$ total de plantas; $\mathrm{x}=$ grau máximo da escala.
Outro aspecto a ser considerado neste estudo é a determinação da melhor época de avaliação. Diferentes períodos de avaliação foram utilizados em estudos realizados por RAVA et al. (1996), que avaliaram a reação de genótipos de feijoeiro aos 11 dias após a inoculação, e NASCIMENTO et al. (1995) que realizaram avaliações aos 25 e 30 dias após a inoculação. Esses últimos verificaram que apenas as variedades FT 120 e PI 207262 e as linhagens IAPAR LP 88141 e IAPAR LP 88-198 não confirmaram a reação de resistência, apresentada aos 25 dias, quando avaliadas 30 dias após a inoculação. Pode-se verificar que as maiores variações no

Ciência Rural, v. 32, n. 1, 2002. 


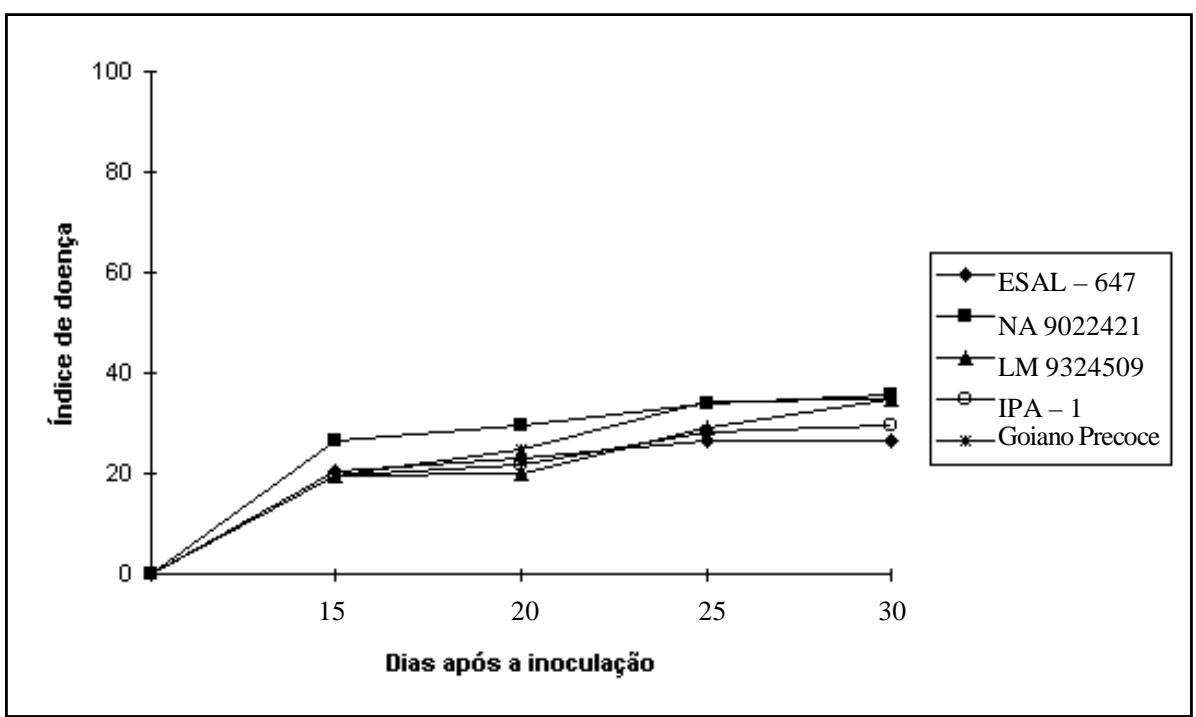

Figura 1 - Evolução da doença em algumas cultivares e linhagens de feijoeiro inoculadas através do método de perfuração do solo. Recife, 1999.

comportamento das cultivares e linhagens avaliadas (Tabela 1) ocorreram entre o $15^{\circ}$ e $20^{\circ}$ dia após a inoculação. Apenas as cultivares ESAL 647 e AN 9022421 e a linhagem LM 9220363 não confirmaram suas reações na transição entre o $25^{\circ} \mathrm{e}$ o $30^{\circ}$ dia, tendo sido, neste estudo, este último o melhor período para avaliar a reação das cultivares e linhagens.

As reações apresentadas pelas cultivares IPA 9 (R) e IPA 7 (I) não coincidiram com aqueles obtidos por RAVA et al. (1996). Esta discrepância pode ser atribuída a diversos fatores como condições

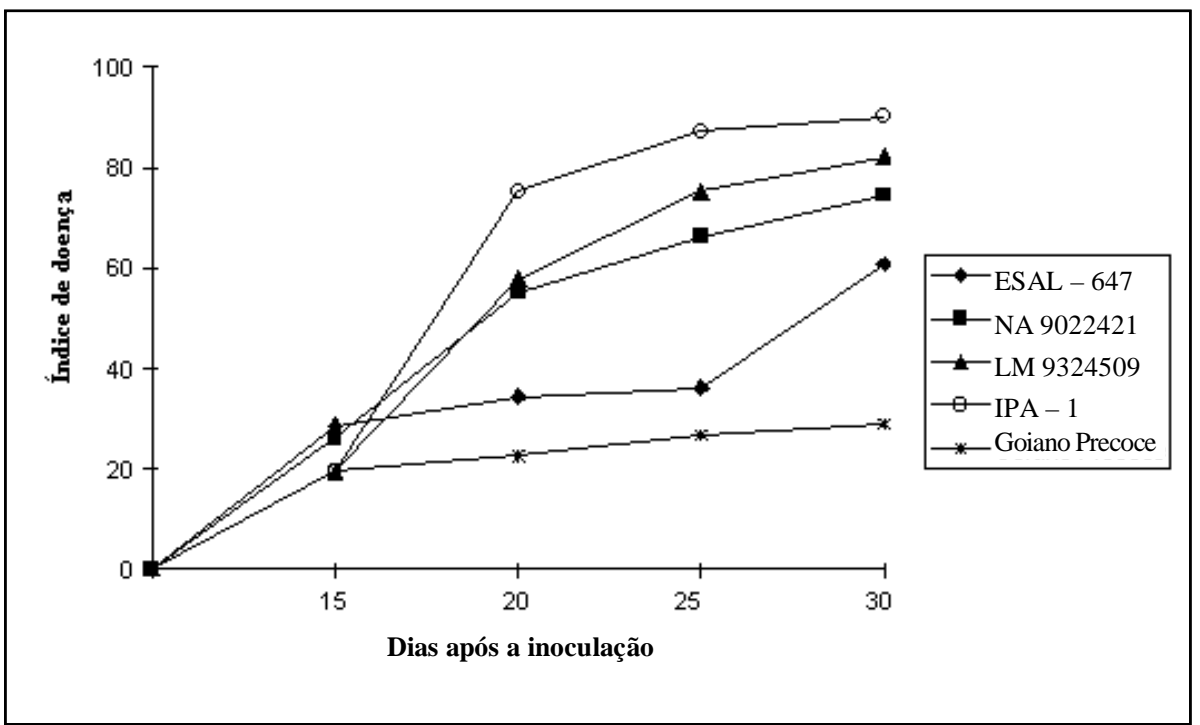

Figura 2 - Evolução da doença em algumas cultivares e linhagens de feijoeiro inoculadas através do método de imersão de raízes. Recife, 1999. de realização do experimento, condições ambientais, agressividade do isolado utilizado e forma de avaliação. O comportamento de resistência da cultivar Goiano Precoce esteve de acordo com os relatos de BALARDIN et al. (1990)

NASCIMENTO et $\boldsymbol{a l}$. (1995), devendo esta cultivar, juntamente com as cultivares $\mathrm{RH}$ 3104 e IPA 9, serem alvos de novos estudos visando a obtenção de cultivares e linhagens melhoradas, com alto nível de resistência à murcha de Fusarium.

A maior eficiência do método de imersão de raízes veio dar suporte e ratificar a sua utilização. Além disso, também possibilitou a identificação da cultivar Goiano Precoce como genótipo altamente resistente. Essa cultivar, além de representar uma promissora fonte de resistência para programas de melhoramento genético, deve ser alvo de estudos posteriores, que envolvem os mecanismos de defesa bioquímicos e/ou estruturais expressos neste patossistema, devido ao seu comportamento de resistência, mesmo através de método de inoculação altamente seletivo.

\section{CONCLUSÕES}

O método de inoculação através da imersão de raízes em suspensão de conídios apresentou-se superior ao método de ferimentos no sistema radicular por meio de perfuração no solo, com posterior deposição de suspensão de conídios, na diferenciação das reações das cultivares testadas nesse estudo.

As cultivares

Goiano Precoce, RH 3104 e IPA-9 apresentaram os menores índices médios de infecção, sem alteração na reação de resistência, em todas as avaliações. 


\section{REFERÊNCIAS BIBLIOGRÁFICAS}

BALARDIN, R.S.; PASTOR-CORRALES, M.A.; OTOYA, M.M Resistência de germoplasmas de feijão (Phaseolus vulgaris L.) a Fusarium oxysporum f. sp. phaseoli. Fitopatologia Brasileira. Brasília, v.15, n.1, p.102-103, 1990.

CRUZ, B.P.B.; TERANISHI, J.; ISSA, E., et $\boldsymbol{a l}$. Resistência de cultivares de feijão-vagem à murcha de Fusarium. O Biológico, São Paulo, v.40, n.1, p.25-32, 1974

FERREIRA, R.G. População fúngica em sementes de feijão (Phaseolus vulgaris L.), fontes de resistência e controle químico a Fusarium oxysporum Schlecht f. sp. phaseoli Kendrick e Snyder. Recife, 1983. 101p. Dissertação (Mestrado em Fitossanidade) - Curso de Pós-graduação em Fitossanidade, Universidade Federal Rural de Pernambuco, 1983

INSTITUTO BRASILEIRO DE GEOGRAFIA E ESTATÍSTICA. Produção vegetal. Anuário Estatístico do Brasil, v.55, cap.3, p.20-47, 1993.

INSTITUTO BRASILEIRO DE GEOGRAFIA E.ESTATÍSTICA. Produção vegetal. Anuário Estatístico do Brasil, v.58, cap.3, p.23-39, 1998.

NASCIMENTO, S.R.C.; MARINGONI, A.C.; KUROZAWA, C. Comportamento de variedades e linhagens de feijoeiro ao Fusarium oxysporum f. sp. phaseoli. Fitopatologia Brasileira, Brasília, v.20, n.3, p.458-463, 1995.

NASCIMENTO, S.R.C.; MARINGONI, A.C ; KUROZAWA, C. Determinação do efeito da concentração e do tipo de inóculo na severidade dos sintomas da murcha de Fusarium em feijoeiro. Summa Phytopathologica, Piracicaba, v.24, n.1, p.8-11, 1998 .

PASTOR-CORRALES, M.A.; ABAWI, G.S. Reactions of selected bean germ plasms to infection by Fusarium oxysporum f. sp. phaseoli. Plant Disease, St. Paul, v.71, n.11, p.990-993, 1987.

PIZA, S.M.T. Patogenicidade de Fusarium oxysporum f. sp. phaseoli e reação de germoplasma de feijoeiro (Phaseolus vulgaris L.). Summa Phytopathologica, Piracicaba, v.19, p.165-167, 1993.

RAVA, C.A.; SARTORATO, A., COSTA, J.G.C. Reação de genótipos de feijão comum ao Fusarium oxysporum f. sp. phaseoli em casa-de-vegetação. Fitopatologia Brasileira, Brasília, v.21, p.296-300, 1996

ROCHA JÚNIOR, W.; SANTOS, J.B.; MENDES-COSTA, M.C. Reação de cultivares e linhagens de feijão à Fusarium oxysporum f. sp. phaseoli. Fitopatologia Brasileira, Brasília, v.23, n.3, p.407-409, 1998.

RIBEIRO, C.A.G.; FERRAZ, S. Resistência varietal do feijoeiro (Phaseolus vulgaris L.) a Fusarium oxysporum f. sp. phaseoli. Fitopatologia Brasileira, Brasília, v.9, n.1, p.3744, 1984 .

SARTORATO, A.; RAVA, C.A. Principais doenças do feijoeiro comum e seu controle. Brasília : EMBRAPA CNPAF, 1994. 300p

SCHOONHOVEN, A.A.S.; PASTOR-CORRALES, M.A. Standard system for the evaluation of bean germplasm Cali : CIAT, 1987. 54p.

ZAMBOLIM, L.; VIEIRA, C.; ARAÚJO, C.A.A., $\boldsymbol{e} \boldsymbol{t} \boldsymbol{a l}$ Ocorrência de murcha de Fusarium na Zona da Mata de Minas Gerais. Fitopatologia Brasileira, v.12, n.3, p.287288, 1987. 